\title{
Diplopia as first symptom of multiple sclerosis
}

\author{
Diplopia como primeiro sintoma de esclerose múltipla
}

Maria Auxiliadora Monteiro Frazão', Aline Cristina F. Lui', Charles Peter Tilbery², Fábio Ejzenbaum¹, Ralph Cohen ${ }^{1}$

\begin{abstract}
Purpose: To determine the frequency and clinical features of the extrinsic ocular motility changes in patients with multiple sclerosis living in the state of Sao Paulo (Brazil), consecutive cases series from 1996 to 2011. Methods: Eighty-three consecutive multiple sclerosis subjects were enrolled, aged from 17 to 59 years. All patients had a history taking and a comprehensive ocular exam. Results: Extrinsic ocular motility changes was detected in 17 (20,48\%) out of 83 individuals. Diplopia as the first symptom of the disease occurred in $11(13,25 \%)$ individuals. Conclusion: Frequency of diplopia as first symptom of multiple sclerosis is relevant. According to this statement, crucial importance should be given concerning spreading of knowledge and skills to internal medicine and general ophthalmology practicing physicians about early diagnosis of multiple sclerosis, which would reduce a delay in diagnosis of the disease and would help patients in the prognosis of the disease which they endure.
\end{abstract}

Keywords: Multiple sclerosis/complications: Diplopia/etiology: Sign and symptoms; Early diagnosis; Ocular manifestations

\section{RESUMO}

Objetivo: Determinar a frequência e as características clínicas das alterações da motilidade ocular extrínseca em indivíduos portadores de esclerose múltipla, residentes no estado de São Paulo, em série de casos consecutivos de 1996 a 2011. Métodos: Foram selecionados oitenta e três indivíduos com esclerose múltipla, com idade entre 17 e 59 anos. Todos foram submetidos à anamnese e exame ocular completo. Resultados: Alterações da motilidade ocular extrínseca foram encontradas em 17 (20,48\%) dos 83 indivíduos. A diplopia ocorreu como primeiro sintoma da doença em 11 (13,25\%) indivíduos. Conclusão: A frequência de diplopia como primeiro sintoma de esclerose múltipla é relevante. Por esse fato, é fundamental ressaltar a importância da difusão do conhecimento desse achado para a realização de diagnóstico precoce de esclerose múltipla, tanto para o oftalmologista geral, como para o médico generalista, melhorando assim o prognóstico dos pacientes que dela padecem.

Descritores: Esclerose múltipla/complicações; Diplopia/etiologia; Sinais e sintomas; Diagnóstico precoce; Manifestações oculares

\footnotetext{
1 DepartmentofOphthalmology, Santa Casa de São Paulo, São Paulo, SP, Brazil.

2 Facultyof Medical Sciences, Santa Casa de São Paulo, São Paulo, SP, Brazil; Department of Neurology, Santa Casa de São Paulo, São Paulo, SP, Brazil.
}

Study carried out in the Department of Ophthalmology, Santa Casa de São Paulo, São Paulo, SP, Brazil.

The authors declare no conflict of interest.

Received for publication 28/10/2014 - Accepted for publication 27/11/2014. 


\section{INTRODUCTION}

$\mathbf{M}$ ultiple sclerosis (MS) is a primary, chronic, inflammatory demyelinating disease of the central nervous system (CNS) of unknown etiology, in which myelin is the target of an autoimmune process, with consequential loss of neurological function ${ }^{1}$.

In Latin America and the Caribbean, the incidence is 0.3 to 1.9 per 100,000 subjects/year ${ }^{2}$. The disease affects mostly young adults, $75 \%$ of the cases occurring between ages 10 and 59 . Women are more commonly afflicted than men, in a 2:1 proportion ${ }^{3}$.

Immunogenetic factors have been associated with its development. A significant increase in incidence has been reported, for members of the same family. Furthermore, in these subjects there has been more frequent observation of the presence of some of the major histocompatibility complex antigens of classes I (HLA-A and HLA-B) and II (HLA-D) as well as of correlation with some of the ocular alterations found in this disease ${ }^{4}$.

Infections by Epstein-Barr virus also seem to be associated with this entity ${ }^{5}$, as well as environmental factors ${ }^{6}$.

Clinical manifestations of MS are reduction of motor, sensitive, cerebellar, cognitive, urogenital, mental and visual functions, characterized by periods of exacerbation alternating with periods of remission.

Among the ocular manifestations which may be present along the course of the disease, there are optic neuritides, peripheral retinal vasculitides, pars planitides, uveitides and abnormalities of extrinsic ocular motility ${ }^{7}$.

Among the oculomotor alterations we may point out diplopia, decompensated phorias, convergence insufficiency, cranial nerve palsies, skew deviation, internuclear ophthalmoplegia and nystagmus ${ }^{8}$. Many subjects afflicted by the disease in question develop ocular impairment as a first sign.

Most of the work in the field of ophthalmology concerns the study of optical neuritides associated with MS. Studies covering the disease and the impairment of extrinsic ocular motility are rare.

The purposes of this work were to study the frequency and features of extrinsic ocular motility changes in MS patients living in the state of São Paulo (Brazil).

\section{Methods}

This study was approved by the Ethics in Research Committee of Irmandade da Santa Casa de São Paulo, under Brasil Platform protocol no. CAAE 14168113.2.0000.5479. We studied sequentially subjects born in or coming from the state of São Paulo, in the southeast of Brazil, afflicted by multiple sclerosis, and admitted to CATEM (Mutiple Sclerosis Care Center) for disease follow-up during the period March 1996 to January 2011. Included subjects belonged to a study group for treatment of the disease.

All of them had a defined clinical diagnostic of MS, confirmed by cerebrospinal fluid analysis and evidence of demyelination by brain MRI. Diagnostic confirmation of the disease followed McDonald's modified criteria, respecting clinical and laboratory manifestations of variation in time and space ${ }^{9}$. We excluded subjects with a possible association with another neurological or systemic disease (systemic lupus erythematosus, polyarteritis nodosa, HTLV-1, AIDS, Behçet's disease, sarcoidosis, syphilis, and Lyme disease) which could have ocular repercussions.
Subjects underwent ocular examinations carried out by two experienced ophthalmologists, consisting of medical history taking, visual acuity (VA) measurement for distant and near vision with the best optical correction using Snellen and Jaeger charts respectively, evaluation of extrinsic ocular motility and of pupillary reflexes, biomicroscopic examination of anterior and posterior segments using a Goldmann three-mirror lens, applanation tonometry, direct and indirect ophthalmoscopy, and computer perimetry with automated perimeter model Humphrey 630, central threshold program.

In case of discordance between the ophthalmologists with respect to examination findings of a given subject, a third ophthalmologist was called in to examine him, and the three examinations were then confronted. If there was no agreement among at least two ophthalmologists, the subject was excluded from the study.

The sample comprised eighty-three subjects. Sixty-one subjects $(73.4 \%)$ were female, and twenty-two $(26.6 \%)$, were male. Their age varied between 17 and $59(M=35.67 \pm 8.68)$. Sixtythree subjects $(97.5 \%)$ where white and two $(2.4 \%)$ were black.

\section{Results}

The results presented are based on ocular findings at the time of the examination and information from subjects obtained during medical history taking.

Alterations of extrinsic ocular motility were identified in $17(20.48 \%)$ of the 83 subjects. Of the 17 subjects, $15(18 \%)$ presented horizontal diplopia due to internuclear ophthalmoplegia, which represents $88.23 \%$ of subjects afflicted with ocular motility alterations. In 11 of the 83 subjects (13.25\%), diplopia was the first clinical manifestation of the disease.

With respect to the evolution characteristics of diplopia, as reported by the subjects, we could observe that their duration ranged from 5 days to 2 months ( $M=29$ days). Diagnostic was immediate in 2 cases. In the others, the interval between the first outbreak and MS diagnosis varied between 5 days and 15 years(M=1349 days). In 4 cases, there was spontaneous regression of diplopia.

Lateral rectus muscle paralysis was observed in 2 (2.4\%) subjects, and it was the first manifestation of the disease for one of them. For the other subject, this alteration manifested 6 months after the first outbreak of the disease. The first subject remained squint-eyed. Nystagmus was observed in one of the subjects afflicted with diplopia.

\section{Discussion}

MS is presumed rare in Brazil, although there are no concrete epidemiological studies up to now. Studies relating to ocular alterations are also scarce in Latin American countries. Those rare existing publications are restricted more specifically to neuro-ophthalmic findings such as optical neuritis ${ }^{10}$.

However, in 2000, Frazão-Sibinelli et al. reported in their study on ocular findings in MS that alterations in extrinsic ocular motility were the second most frequently observed manifestation observed. In a series of 64 subjects, 8 (12.5\% ) presented diplopia, and in 6 it was also mentioned as the first sign of the disease, similarly to the results found in this study, thus alerting the ophthalmologist to the importance of knowing that diplopia can be a precursor to the disease ${ }^{11}$. 
Internuclear ophthalmoplegia (INO) is the most common cause of abnormalities in ocular movement and of diplopia in MS, having been reported in approximately $53 \%$ of cases ${ }^{12}$. In our sample, diplopia occurred in 15 subjects (18\%) of the 17 who presented alterations in extrinsic ocular motility, representing $88.23 \%$ of subjects afflicted with alterations in ocular motility. In 11 of the 83 subjects $(13.25 \%)$, diplopia was the first clinical manifestation of the disease. However, other studies do not mention this alteration as the first manifestation of the disease, but rather as a symptom occurring in one of its phases. As these subjects have been under our constant monitoring, there is the possibility of being able to observe the appearance of this alteration in a later phase of the disease in a larger number of patients, which may cause an increase in the incidence of this alteration, drawing close to that reported in the literature.

Incidence of bilateral INO is considered highly suggestive of MS, especially in younger subjects. The most logical explanation rests in the location of the lesions, since many of them are located in the periventricular white matter, the exact site of the medial longitudinal fasciculus (MLF), responsible for INO. Although the classical description of this condition is unilateral adduction deficiency accompanied by nystagmus in the contralateral eye, subjects in this study presented in most cases only a slight adduction deficit or sometimes only a delay in the abduction movement. There was only one observed case of nystagmus. The presence of nystagmus, in this case, can be explained since part of the structures controlling this movement, as well as vergence alterations, are located close to the MLF.

It is important to remember that these cases can have other associated findings such as nystagmus, skew deviation and vergence alterations, since part of the structures controlling these movements are located close to the MLF.

Although MS is not a common cause for cranial nerve palsy, its frequency increases in young subjects, predominantly as pair VI palsy ${ }^{13}$. Two of the subjects in this study presented pair VI palsy. One of them was aged 28 and the other one 39, corroborating findings in the literature.

Described alterations which should not be forgotten are supranuclear defects and nystagmus ${ }^{14}$. The most common type of nystagmus is extreme gaze evoked nystagmus ${ }^{15}$, in which the tremor manifestations occur mostly on adduction and abduction. Although nystagmus has been reported largely in subjects with $\mathrm{MS}^{16}$, we observed it in only one subject in our study.

Subjects with ocular symptoms consistent with an MS attack should be questioned about previous symptoms. When diplopia occurs in young adults, the multiple sclerosis hypothesis should always be remembered, especially in cases of internuclear ophthalmoplegia ${ }^{17}$. We can say that ocular findings in MS are frequent and often the first clinical manifestation of the disease. Although optical neuritis is the most commonly observed alteration, we should stress the possibility of other ocular alterations preceding or accompanying the course of the disease, as demonstrated in this study.

\section{Conclusion}

The frequency of diplopia as first symptom of multiple sclerosis is relevant. Due to this fact, it is fundamental to stress the importance of spreading the awareness of this finding for early diagnosis of multiple sclerosis, both to general ophthalmologists and to general practicing physicians, thus improving the prognosis of patients afflicted by the disease.

\section{ReferenCes}

1. Traboulsee A, Paty D. Magnetic resonance imaging in disease progression in multiple sclerosis. In: Dangond F editor. Disorders of myelin in the central and peripheral nervous systems. Boston: Butterworth-Heinemann; 2002. p.170.

2. Cristiano E, Rojas J, Romano M, Frider N, Machnicki G, Giunta D, Calegaro D, Corona T, Flores J, Gracia F, Macias-Islas M, Correale J. The epidemiology of multiple sclerosis in Latin America and the Caribbean: a systematic review. MultScler. 2013;19(7):844-54.

3. Alonso A, Hernán MA Temporal trends in the incidence of multiple sclerosis: a systematic review. Neurology. 2008;71(2):129-35.

4. Benešová $Y$, Vaškù $A$, Stouraè $P$, Hladíková $M$, Fiala $A$, Bednaøík J. Association of HLA-DRB1*1501 tagging rs3135388 gene polymorphism with multiple sclerosis. J Neuroimmunol. 2013;255 $(1-2): 92-6$.

5. Serafini B, Muzio L, Rosicarelli B, Aloisi F. Radioactive in situ hybridization for Epstein-Barr virus-encoded small RNA supports presence of Epstein-Barr virus in the multiple sclerosis brain. Brain. 2013;(Pt7):e233.

6. Disanto G, Morahan JM, Ramagopalan SV. Multiple sclerosis: risk factors and their interactions. CNS NeurolDisord Drug Targets. 2012;11(5):545-55.

7. The clinical profile of optic neuritis. Experience of the Optic Neuritis Treatment Trial. Optic Neuritis Study Group. Arch Ophthalmol. 1991;109(12):1673-8.

8. Jenkins PF. The multiple facets of multiple sclerosis. AmOrthopt J. 2007; 57:69-78.

9. Polman CH, Reingold SC, Banwell B, Clanetpara M, Weinshenker B, Wolinsky JS, et al. Diagnostic criteria for multiple sclerosis: 2010 Revisions to the McDonald criteria. Ann Neurol. 2011;69(2):292-302.

10. Fernandes DB, Ramos R de I, Falcochio C, Apóstolos-Pereira S, Callegaro D, Monteiro ML. Comparison of visual acuity and automated perimetry findings in patients with neuromyelitisoptica or multiple sclerosis after single or multiple attacks of optic neuritis. J Neuroophthalmol. 2012; 32(2):102-6.

11. Sibinelli-Frazão MA, Cohen R, Ramalho AM, Tilbery CP, Lake J. Manifestações oculares em pacientes portadores de esclerose múltipla em São Paulo. Arq BrasOftalmol. 2000 3(4):233-43.

12. Frohman EM, Frohman TC, O'Suilleabhain P, ZhangH,Hawker $\mathrm{K}$, Racke,et al. Quantitative oculographiccharacterisation of internuclear ophthalmoparesis in multiple sclerosis: the versionaldysconjugacy index Z score. J NeurolNeurosurg Psychiatry. 2002;73(1):51-5.

13. Rush JÁ, Younge BR. Paralysis of cranial nerves III, IV and IV: causes and prognosis in 1000 cases. Arch Ophthalmol. 1981;99(1):77-9

14. Pula JH, Brock K, Kattah JC. Clinical course of patients with ophthalmoplegia caused by radiographically detectable brainstem demyelination occurring asa clinically isolated demyelinating syndrome. J Neuroophthalmol. 2011;31(3):234-8.

15. SubeiAM,Eggenberger E. Efferent manifestations of multiple sclerosis. CurrOpinOphthalmol. 2012;23(6):506-9.

16. Graves J, Balcer LJ. Eye disorders in patients with multiple sclerosis: natural history and management. ClinOphthalmol. 2010; 4:1409-22.

17. Roodhooft JM. Ocular problems in early stages of multiple sclerosis. Bull SocBelgeOphtalmol. 2009;(313): 65-8.

\section{Corresponding author:}

Maria Auxiliadora M. Frazão

E-mail: sibi@uol.com.br 